The available information suggests that the extraordinarily specialized behaviour of the bower-birds is an immensely complicated development of avian territorialism. The chronology of the events in relation to spermatogenesis, no less than the detailed sequence of the behaviour itself, is in accord with this idea. The need for such behaviour arises from the fact that it is advantageous for any male to secure his territory and mate as early as possible, for competition is often severe, while it may be highly disadvantageous for reproduction to begin until much later in the year when adequate food for the young is available.

In addition to an elaboration of this kind, there is the extraordinary substitution of inanimate objects for the primary sexual stimulus, a process which would be termed fetishism in human psychopathology. This curious development directs attention to the way in which individual culturally determined acts in man so frequently have parallels in the specifically characteristic behaviour of birds.

\section{HEALTH OF THE SCHOOL CHILD}

IN "The Health of the School Child", the report for 1948-49 of the Chief Medical Officer to the Ministry of Education (London: H.M.S.O., 1952. Pp. 92. 3s. net), it is stated that the children in Great Britain are healthier than ever before in our history.

The numbers of under-nourished school children are now so small that school medical officers do not consider that the subject calls for special mention. Some of them, however, give data on heights and weights. Between 1939 and 1949, London school children gained an average of $\frac{3}{4} \mathrm{in}$. in height and $1 \frac{3}{4} \mathrm{lb}$. in weight. A striking feature was that the changes in height and weight were proportionate; while the greatest improvement had been in districts above average in 1938, there had also been a definite improvement in the worst areas. Children were not merely taller and heavier than their parents but were members of a generation altogether of greater physique. Figures relating to 5-year-old children in Wolverhampton showed that girls gained an average of over $6 \frac{1}{2}$ in. in height and more than $8 \mathrm{lb}$. in weight between 1909 and 1949 ; boys gained an average of nearly $4 \frac{1}{2} \mathrm{in}$. and $6 \frac{1}{2} \mathrm{lb}$. during the same period. Weighing machines in senior schools in this area were no longer adequate for pupils in their last year.

During the period 1939-49, the school meals service multiplied roughly seventeen times and had changed out of all recognition. With restrictions on the building of new canteens, the report suggests concentration on stabilizing and improving the existing service. The development of training courses for staffs at all levels is proposed. The lack of courses for women who serve the meals is unfortunate, particularly since reports on food poisoning frequently attributed the trouble to lack of knowledge in the canteens.

Figures for October 1949 showed that $53 \cdot 2$ per cent of the children present $(2,851,000)$ took school dinners, and there were 23,000 canteens serving 27,000 schools. 1,950 schools were then without school meals facilities. In addition, 86.9 per cent ( $4 \frac{2}{3}$ millions) of the children present took milk in school. More than 98 per cent of the milk was either tuberculin-tested or pasteurized.

During 1948, 96,262 school children had tonsil operations. The following year the figure fell to
69,449 . The large number of operations in 1948 the figure was only exceeded in 1929-30-31-was mainly due to the widespread poliomyelitis epidemic in 1947. This caused the postponement of operations which would have been carried out in that year. The report stresses that tonsillectomy is scarcely ever an urgent operation and that only cases in need of urgent treatment should be referred to hospital for operative treatment. It is becoming increasingly realized that tonsillectomy is not a trivial operation and should not be treated lightly. Cases that are not urgent should be kept under observation for at least three months before being referred to a surgeon. All cases put on hospital lists should be examined periodically, since experience has shown that many who had been on a waiting list for a long time no longer required treatment. It is more important to deal safely and efficiently with a few children than to operate on large numbers, many of whom are in no need of urgent treatment.

The serious effect of the National Health Service on the school dental service is discussed. Because of the higher incomes obtainable under the new general dental service, many school dentists resigned to enter private practice. By the end of 1949 , the number of school dental officers was 884 (equal to 732 full-time officers), compared with 1,063 (921 full-time) in 1947. In eighteen months, the service had lost one-fifth of its strength and was back to its war-time position.

There are signs in some areas that the improvement in the teeth of school children during and just after the War is on the wane. One report suggested that sticky buns given by mothers to restive young children was the possible cause of "the deplorable teeth so often seen in children between 5-7 years".

Nearly 450,000 school children ( 8 per cent of those on the registers) were found to be in a verminous condition in 1949. This was "profoundly disappointing" and showed no improvement on post-war years. In 1948, more than $4 \frac{1}{2}$ million school children - probably more than half of those on the registerswere medically examined or re-examined, other than for dental disease or verminous condition. The incidence figures for the various defects showed no major changes from those of 1947, though increases in the number of cases of defects of vision and speech needing treatment were recorded.

The new outlook on physical education is commented upon, and the growth of interest and skill in athletics noted. In Wales, athletics had made considerable headway where hitherto progress had been slow. The Midland and South-Western Divisions also reported an increase in the popularity of athletics; in the North-Western Division it was "probably the one aspect of physical education in which improvement was most obvious".

The report contains a special chapter on the problems of diabetic children. England is believed to be the only country in the world providing hostels for these children; but the report stresses that while such accommodation is indispensable for a minority of diabetic children, the great majority should remain at home since there was no substitute for a good home. The report also contains chapters on the co-ordination of the school health service with the National Health Service, the treatment of defective vision, and the prevention of tuberculosis in school children.

The cost of the school health service and special schools, which was $\mathfrak{1 0 , 1 9 4 , 0 0 0}$ in $1947-48$, fell to $£ 9,234,000$ in $1948-49$. 